\title{
A política escolar na França na atualidade (2017-2019): tentativas de interpretação ${ }^{12}$
}

\author{
School politics in France today (2017-2019): essay for interpretation ${ }^{1}$ \\ La politique scolaire en France aujourd'hui (2017-2019): essai d'interprétation
}

André D. Robert ${ }^{3}$

Universidade de Lyon II - França

\begin{abstract}
Resumo: Este artigo tenta analisar os dois anos (2017-2019) da política escolar conduzida na França pelo ministro Jean-Michel Blanquer no governo do novo presidente Emmanuel Macron. Esta política é de fato particularmente difícil de descriptografar, na medida em que não pretende ser nem de direita, nem de esquerda. $O$ autor analisa primeiro o quadro ideológico e teórico dessa política (no centro do qual, encontra-se o neoliberalismo e a neurociências), em seguida, alguns aspectos da comunicação e da ação do ministro que busca muitos efeitos midiáticos, enfim os principais significados da lei conhecida como "escola de confiança", promulgada em julho de 2019. Essa análise mostra que por trás das boas intenções declaradas de luta contra o fracasso escolar, se esconde uma política autoritária caracterizada por uma desconfiança em torno de professores e orientações desiguais, reforçando a seleção em detrimento dos alunos com maior dificuldade.
\end{abstract}

Palavras-chave: Política educacional na França. Neoliberalismo. Neurociências. Seleção escolar.

Abstract: This article attempts to analyse the two years (2017-2019) of school policy conducted in France by the Minister of Education Jean-Michel Blanquer in the governments of the new President Emmanuel Macron. Indeed, this policy is particularly difficult to decipher insofar as it claims to be neither right nor left. The author first analyses the ideological and theoretical framework of this policy (within which we find neo-liberalism and neuroscience), then some aspects of the communication and the actions of the minister who seeks a lot of media attention. Finally, the main principles of the so-called law of "the school of trust" promulgated in July 2019. This analysis shows that behind the declared good intentions of tackling school failure hides an authoritarian policy characterised by a lack of trust towards teachers and bias during selection, to the detriment of the students most in need.

\footnotetext{
${ }^{1}$ Uma primeira versão em francês deste texto (pouco modificado) foi publicada no Carnets rouges, n ${ }^{\circ} 17,2019$. Agradeço a esta revista por permitir uma versão em português.

2 Tradução: Leonardo Moreira Ulhôa: É graduado em Geografia e em Letras - Língua e Literatura Francesa pela Universidade Federal de Uberlândia. Desenvolve pesquisas relacionadas, principalmente, à iconografia de livros didáticos. Em 2013, defendeu a tese de doutorado intitulada: "Imagens e estereótipos do Brasil nos livros didáticos franceses”. Atualmente, é coordenador da Divisão de Capacitação da Universidade Federal de Uberlândia e professor de língua francesa na Central de Línguas desta mesma instituição. E-mail: lulhoa@yahoo.com.br; Lattes: http://lattes.cnpq.br/8336167195293919.

Zeina Abdulmassih Khoury: Doutora em Letras pela Universidade de São Paulo e docente do Instituto de Letras e Linguística da Universidade Federal de Uberlândia. Realiza pesquisas na área da didática de ensino e aprendizagem de línguas estrangeiras, especialmente sobre o Francês para Fins Específicos (FOS) e o Francês para Fins Universitários (FOU). É coordenadora do Centro aplicador dos exames DELF e do Idioma Sem Fronteiras - Francês - da Universidade Federal de Uberlândia. E-mail: zeinakhoury10@gmail.com; ORCID: https://orcid.org/0000-0002-8697-7765.

Lattes: http://lattes.cnpq.br/4427447725519454.

3 Professor Emérito da Universidade de Lyon II - França. E-mail: andre.robert@,univ-lyon2.fr. ORCID: https://orcid.org/0000-0002-3834-0866.
} 
Keywords: France. School policy. Neoliberalism. Neurosciences. School selection.

Résumé: Cet article essaie d'analyser les deux ans (2017-2019) de politique scolaire menée en France par le ministre de l'Education Jean-Michel Blanquer dans les gouvernements du nouveau président Emmanuel Macron. Cette politique est en effet particulièrement difficile à décrypter dans la mesure où elle prétend être ni de droite ni de gauche. L'auteur analyse d'abord le cadre idéologique et théorique de cette politique (au centre duquel on trouve le néolibéralisme et les neurosciences), puis quelques aspects de la communication et de l'action du ministre qui recherche beaucoup les effets médiatiques, enfin les principales significations de la loi dite « de l'école de la confiance » promulguée en juillet 2019. Il ressort de cette analyse que, derrière les bonnes intentions déclarées de lutte contre l'échec scolaire, se cachent une politique autoritaire caractérisée par une défiance envers les enseignants et des orientations inégalitaires renforçant la sélection au détriment des élèves les plus en difficulté.

Mots-clés : France. Politique scolaire. Néolibéralisme. Neurosciences. Sélection scolaire.

Recebido em: 03 de setembro de 2019 Aceito em: 27 de outubro de 2019

\section{Introdução}

Em meados do verão de 2019, mais precisamente no dia 28 de julho, foi publicada, no Diário Oficial da República Francesa, uma nova lei que se intitula "escola de confiança" ". Ela leva o nome do ministro da Educação Nacional, Jean-Michel Blanquer, cargo por ele ocupado desde a primavera de 2017. Na França, uma lei, quando geralmente proposta por um ministro em nome do governo, é o resultado de uma intenção primeira (um homem, seu gabinete, as pessoas e as teorias de referência que o inspira) e da intervenção de duas assembleias legislativas (a Assembleia Nacional, que, neste caso, tem a maioria governista ${ }^{5}$; o Senado, atualmente, em sua maioria, oposição), reunidas, por fim, em uma comissão mista. Nos últimos anos, em razão das alternâncias entre direita e esquerda, sucederam-se, na França, várias leis destinadas a reformar profundamente a educação: em 2005, sob a presidência de Nicolas Sarkozy, a lei "para o futuro da escola" (conhecida como lei Fillon, devido ao nome do ministro); em 2013, sob a presidência de François Hollande, a lei de "refundação da escola" (conhecida como lei Peillon) ${ }^{6}$. Assim, submetidos a permanentes reformas, os professores, às vezes, queixam-se das dificuldades em perceber os verdadeiros significados destas leis. Hoje, em particular, esta ausência de sentido se faz sentir porque a política conduzida pelo ministro Blanquer é difícil de ser interpretada de maneira unívoca.

\footnotetext{
${ }^{4}$ https://www.education.gouv.fr/cid143616/28-juillet-2019-promulgation-de-loi-pour-une-ecole-de-la-confiance.html

${ }^{5}$ Isto é, favorável ao presidente eleito em maio de 2017, Emmanuel Macron.

${ }^{6}$ Cf. André D. Robert, L'école en France de 1945 à nos jours, Grenoble, PUG, 2 e édition augmentée.
} 
Mais do que o conteúdo em definitivo da lei (embora um pouco modificado, mas mantendo a sua marca inicial), o que vai nos interessar aqui é decifrar a política de um ministro que se vale do posicionamento macronista, supostamente "nem de direita nem de esquerda"; entendimento bastante obscuro porque algumas medidas procuram ser tidas como progressistas (no sentido tradicional deste adjetivo, isto é, direcionadas para o progresso social, favoráveis às classes populares) e, no entanto, poderiam sê-las apenas em aparência. Esta tentativa de leitura presume interrogar vários elementos que convergem para a elaboração da política ministerial: - o quadro ideológico, se não teórico (em momento oportuno, veremos que este qualificativo é reivindicado pelo interessado), no qual se fundamenta o atual projeto de ação e de transformação; - a comunicação e a ação no dia a dia, as decisões tomadas, seus primeiros efeitos, seu significado (evidentemente compreendidos a partir dos posicionamentos filosóficos e políticos do analista, adotando uma postura crítica, mas evitando se colocar no contraponto da militância); - por fim, a síntese realizada no projeto de lei, que pretende tornar coerentes as pretensões, as ideias e as medidas concretas para o futuro.

\section{O quadro teórico-ideológico da política Blanquer:}

Para entender este quadro, basta visualizar as publicações deste homem pertencente ao núcleo da Educação Nacional, Jean-Michel Blanquer (professor de Direito, antigo reitor e antigo Dgesco ${ }^{7}$ ) e, em particular, a obra de sua autoria, publicada em 2016, durante a sua campanha, como uma espécie de manifesto-programa: L'École de demain: Propositions pour une Éducation nationale rénovée $e^{s}$ Longe de parecer simplista, este curto livro (152 páginas) é escrito de maneira simples com o objetivo de alcançar um vasto público, como convém à ocasião de uma campanha eleitoral. Assinado pelo nome do futuro ministro, este livro é explicitamente reivindicado como fruto de um trabalho coletivo realizado no âmbito do Instituto Montaigne. Este instituto, em funcionamento desde o ano 2000, é um think tank projetado por patrões e executivos declaradamente ligados à ideologia liberal ou neo-liberal. De fato, se o uso da noção de liberdade - que ocupa grande parte da introdução - não é suficiente para caracterizar todo o projeto como sendo liberal em razão da polissemia deste termo, pelo menos a recorrência a ele não é incompatível com a orientação geral do liberalismo (entendido no duplo sentido econômico e antropológico). Contudo, o essencial ainda não está aí: ele reside na afirmação, reiterada ao longo dos capítulos, da possibilidade de resolução de todos os problemas do sistema educativo francês por meio da ciência. Neste

\footnotetext{
${ }^{7}$ Diretor geral do ensino escolar, importante cargo da administração e muito próximo do ministro.

${ }^{8}$ Paris, Odile Jacob.
} 
caso, as neurociências, baseando-se no estudo objetivo de imagens cerebrais (em especial pela IRM $^{9}$ ) e pretendendo determinar os únicos verdadeiros métodos de aprendizagem, os quais levam em conta a multiplicidade de inteligências (o que, de fato, conduz a dessociologizar e despolitizar a abordagem da relação com os saberes dos sujeitos sociais). Jean-Michel Blanquer afirma que se trata de "construir um método de objetivação [entendam: método científico incontestável] a serviço da liberdade” (p.12). Associado ao seu mentor cientista Stanislas Dehaene, professor de psicologia cognitiva no prestigioso Collège de France, e inscrevendo-se, sem o dizer, em uma corrente neuro-pedagógica já existente há muito tempo nos Estados Unidos ${ }^{10}$, o ministro pretende transformar, e até mesmo revolucionar, a educação em profundidade (p.140), com a ajuda de uma "ciência" sobre a qual ele tem uma concepção - ainda que ele se defenda - cientificista, mecanicista e aplicacionista.

Cada um dos seis capítulos que compõem o livro repete, assim, a mesma perspectiva: o que nos ensina a experiência; o que nos ensina a comparação internacional; o que nos ensina a ciência; o que é preciso"11 fazer (cenário fundamental, ideal); medidas-chave. E, eis como de um toque de mágica, o sistema francês (objetivamente em posição muito mediana nas avaliações internacionais PISA ou PIRLS ${ }^{12}$ ) resolverá suas dificuldades; em particular, aquelas relacionadas ao aprofundamento das desigualdades sociais e ao fracasso escolar! É preciso ressaltar, no entanto, que as decisões de reformas tomadas entre 2007 e 2013, ou seja, sob a presidência de Sarkozy e dos governos de direita de orientação liberal, foram sistematicamente aprovadas pelo Sr. Blanquer (que, é verdade, exercia funções importantes no ministério) e que todas aquelas que datam do quinquênio seguinte foram censuradas. Com base nestes indícios, não se pode duvidar da consolidação política bem à direita do ministro.

\section{Síntese da comunicação e da ação do ministro}

A obra mencionada anteriormente e, por certo, a quantidade de medidas representativas provenientes do questionamento "social” estão direcionadas para o bem dos menos favorecidos e, por alargamento, para o bem comum. Nesse sentido, uma primeira ação inscrita no programa de Emmanuel Macron consistia em dividir o tamanho das salas do

\footnotetext{
${ }_{9}^{9}$ IRM: Imagem por Ressonância Magnética

${ }^{10}$ Cf. Michel Blay et Christian Laval, Neuropédagogie. Le cerveau au centre de l'école, Paris, Tschann, 2019.

${ }^{11}$ Grifo nosso

${ }^{12}$ PISA: Programa Internacional de Avaliação de Estudantes; PIRLS: Estudo Internacional sobre o Progresso em Alfabetização para Leitura.
} 
Cours Préparatoire ${ }^{13}$ por dois, em REP e REP $+{ }^{14}$. Isto, na verdade, tratava-se da sétima medida-chave aplicada no maternelle ${ }^{15}$, conforme previsto na publicação L'École de demain, levando em conta "a ocorrência da dificuldade escolar em determinadas áreas urbanas, periurbanas ou rurais", e com conhecimento de causa do seu custo induzido (estimado em 3500 postos suplementares de professores do primeiro grau, ou seja, cerca de "120 milhões de euros por ano"). A transferência desta medida para a escola primária - em vez da escola maternal - não mudando em nada a sua disposição inicial (combater o mais cedo possível as deficiências de alguns alunos em termos da linguagem), representa, novamente, a preponderância do imperativo econômico da menor despesa e da redução do número de funcionários, uma vez que não seria necessária a criação de postos de trabalho, pois bastaria recorrer aos excedentes de professores que participavam do antigo "PMQDC" ${ }^{16}$. Isto, progressivamente, permitiria pôr-lhe um fim. Assim, se no âmbito das grandes desigualdades territoriais, os postos de trabalho do $1^{\circ}$ grau são criados, na mesma medida, aqueles de $2^{\circ}$ grau serão extintos.

Ainda que esta medida tenha sido objeto de uma primeira avaliação favorável sob a égide da DEPP17 ("os resultados estão no intervalo abaixo dos verificados em outros países, mas são significativos”) ${ }^{18}$ e que ela deva se estender a 300 mil alunos no início do ano letivo de 2019, são-lhe, no entanto, dirigidas críticas concernentes ao seu aspecto fragmentado face às necessidades, à diferença de tratamento entre as zonas classificadas REP e as outras (notadamente as zonas rurais em que o desdobramento teria a sua justificativa), ao aumento quase automático dos efetivos nos outros anos de ensino, CM1 e CM219, em um contexto de política de custo constante ou menor. De qualquer modo, isto não é a revolução anunciada, trata-se apenas da constatação do que a experiência pedagógica, confirmada por algumas pesquisas, pode levar a perceber (individualiza-se mais facilmente e melhor em grupos restritos, sob condições mínimas).

\footnotetext{
${ }^{13} \mathrm{Na}$ França, o ensino primário corresponde aos anos de ensino que atendem as crianças de 6 a 10 anos; em comparação ao Brasil, são os anos inicias do Ensino Fundamental. O Cours Préparatoire, neste caso, é o primeiro nível do ensino primário, destinado às crianças com idades de 6 a 7 anos, em fase de alfabetização.

${ }^{14}$ Os REP são as Redes de educação prioritária, instaladas em áreas socialmente desfavorecidas e concebidas de uma política de discriminação positiva, considerando dar mais recursos aos que têm menos.

${ }^{15}$ Escola destinada às crianças de 3 a 6 anos; no Brasil, corresponde à Educação Infantil.

${ }^{16}$ Plus de Maîtres que de Classes - Mais professores do que salas de aula. Dispositivo instituído pela lei de 2013; consiste em aumentar o número de professores em comparação à quantidade de turmas em uma escola, permitindo, assim, trabalhar em grupos menores, de forma modulada.

${ }_{17}$ Direção de Avaliação, da Prospectiva e do Desempenho, uma das direções administrativas do ministério da Educação Nacional.

${ }^{18}$ Cf. Marc Gurgand, um dos pesquisadores envolvidos, in Le Monde.fr, 23.01.2019.

19 Denominação referente aos dois anos de ensino que encerram o ensino primário na França (de 9 a 10 anos).
} 
Outro aspecto das decisões mais importantes tomadas há dois anos pelo ministro Blanquer diz respeito aos liceus (ensino médio) e ao baccalauréat ${ }^{20}$. Na obra-programa mencionada anteriormente, o capítulo 4, dedicado aos estabelecimentos de ensino do segundo ciclo, para além do termo "liberdade" - reiterado diversas vezes - a palavra-chave é “diferenciação”; e a palavra escondida, por sua vez, parece ser a de seleção. Assim, com base nas "diferentes dificuldades e excelências", trata-se de "privilegiar a diversidade das formações" (p. 75) e de "não renunciar a procura pela excelência desde a entrada no ensino médio, na mais bela tradição francesa, para os alunos que vão aprofundar estas questões no ensino superior" (p. 82). Se, por um lado, é inegável a confirmação das desigualdades sociais apesentadas por meio da frequência atual, seja nos liceus gerais, tecnológicos ou profissionais; por outro, isto se faz pela compartimentação das áreas de conhecimento. A solução para este recorrente problema da organização escolar francesa não é simples e, seguramente, ela não passa por uma intensificação ainda mais precoce e oficializada das "excelências" assim previstas, muito menos por uma hiper-predeterminação ao ensino superior para uns e uma quase exclusão desta possibilidade para outros.

No entanto, é bem este o caminho que o liceu e o baccalauréat Blanquer vêm seguindo a partir dos anúncios do primeiro trimestre de 2018, certamente, após o recebimento de um relatório, porém, sem um real diálogo com os pais, os professores e os seus sindicatos quando se trata de uma transformação de grande dimensão em termos de estruturas e conteúdos. A reforma do liceu, cujas primeiras aplicações entraram em vigor no ano letivo de 2019, baseiase na exclusão de algumas habilitações, diferente de como eram estruturadas anteriormente, tendo como objetivos acabar com a supremacia considerada falaciosa dos conhecidos cursos científicos (classes $\mathrm{S}^{21}$ ) e renovar as cartas, multiplicando as ofertas de opções para os estudantes chamados a exercer a sua liberdade de pré-adultos ou adultos, de tal maneira que possam organizar as suas próprias formações em função das aptidões e preferências (subsiste um núcleo comum no qual se acrescentam 3 e 2 "especialidades"). Trata-se, então, de uma antiga receita liberal já explorada em nível dos colégios pelo projeto Haby, em 197522, bastante criticada por ser uma concepção ilusionista da liberdade de escolhas (que, na realidade, eram socialmente orientadas) conduzindo a possibilidades de eliminação.

O novo exame do ensino médio (baccalauréat) segue, evidentemente, o mesmo modelo. Ele se baseia em quatro provas escritas: francês, em primeiro; duas provas de especialidade no último

\footnotetext{
${ }^{20}$ Exame avaliativo que ocorre no fim do ensino médio, permitindo, assim, que o estudante ingresse no ensino superior.

${ }^{21}$ Classes ditas Científicas que muitos alunos escolhiam (sem competências específicas em ciências) porque abriam caminho para os melhores estudos superiores.

22 Cf. A.D. Robert, Le 'projet de modernisation du système éducatif: prémices proches et lointaines, contexte, processus d'élaboration (été 1974- février 1975) in Gutierrez L. et Legris P., Le collège unique, PUR, 2016.
} 
ano do ensino médio; em seguida, filosofia; e a grande prova oral de 20 minutos, contando como $60 \%$ da média, enquanto os outros $40 \%$ procederão de um acompanhamento contínuo. A crítica de fundo que pode ser feita a esta nova arquitetura, sem reformulação, considera o fato de, fingindo o contrário, correr-se o risco de privilegiar ainda mais os jovens e as famílias informadas das combinações de especialidades mais convenientes para integrar este ou aquele estabelecimento de ensino superior. Em outras palavras, uma seleção que não diz o seu nome e que teria êxito a baixo ruído onde outras políticas falharam no passado, revelando-se no grande dia ${ }^{23}$.

Acrescentemos a isto que, como muitos dos seus antecessores de direita, o ministro Blanquer aprecia, na sua comunicação, a aliança entre o modernismo, do qual pretende fazer proceder as suas reformas, e o tradicionalismo autoritário, que tem sempre os favores da opinião: o desejo de usar o uniforme pelos alunos, o retorno do ditado, a criação de corais, a proibição de celulares no colégio, a bandeira nas salas de aula, a valorização da reprovação, etc.

\section{Outros aspectos da política Blanquer no seu projeto de lei:}

Contradizendo uma de suas declarações iniciais ${ }^{24}$, Jean-Michel Blanquer acabou recorrendo à arma da lei e entregou o projeto "para uma escola de confiança"; registrado no escritório da Assembleia Nacional em 5 de dezembro de 2018 (n. ${ }^{\circ}$ 1481). A apresentação dos motivos é bastante singular, a começar pelas declarações gerais de uso neste tipo de exercício e prosseguindo com um comentário técnico muito plano dos principais artigos que alteram o código da educação, o que faz com que o texto seja privado de toda a altura de visão e do fôlego esperado, sobretudo quando se trata de transformar, senão revolucionar, a educação de um país.

Destacando o aspecto da "exemplaridade" a se fazer pelos funcionários, o artigo $1^{\circ}$ (o seu lugar não é indiferente) soa como um apelo à ordem autoritária. Isto, aliás, foi imediatamente entendido como uma atitude de desconfiança, a priori, mais do que paradoxal em um documento imbuído da ideia de confiança. $\mathrm{O}$ artigo $2^{\circ}$, estendendo-se ao $4^{\circ}$, sem dúvida, são os mais marcantes do ponto de vista simbólico, uma vez que instituem a obrigação escolar aos 3 anos (em vez de 6, como ocorre atualmente ${ }^{25}$ ) e traduzem o desejo de conferir à escola a missão de se opor às desigualdades socioculturais, desde a Educação Infantil. De fato, uma iniciativa amplamente simbólica, porquanto mais de $97 \%$ das crianças francesas já frequentam

\footnotetext{
${ }^{23}$ Cf. a obra ainda a ser publicada : A.D. Robert, 'Alain Peyrefitte, la rénovation de la pédagogie et le colloque d'Amiens', ouvrage collectif, PUR.

24 «Não haverá lei Blanquer, terei orgulho disso» teria declarado o ministro após a sua posse em maio de 2017.

${ }_{25}$ Oficialmente, desde a III República e, também, com a lei de obrigatoriedade escolar de Jules Ferry (28 de março de 1882), a escola tornou-se obrigatória a partir dos 7 anos. Esta idade fora reduzida para 6 anos em 1936, sob o governo da Frente Popular. Hoje, a imensa maioria (mais de 97\%) frequenta a escola gratuita desde os 3 anos, quando até então não era obrigatória, mas oferecida às famílias que a solicitavam.
} 
a escola aos 3 anos (o efeito desta medida deve se fazer sentir somente nos territórios franceses da Guiana e de Maiote, muito atrasados). Todavia, outro efeito pode ser denunciado por alguns prefeitos: a obrigação que lhes é assim imposta de financiar a Educação Infantil privada, que se situava até então fora do âmbito do contrato com o Estado.

Modificando o regulamento das experiências pedagógicas (o reitor Blanquer fomentou o comportamento de Céline Alvarez, que se valia da neuro-pedagogia ${ }^{26}$, e apoiava indefectivelmente as atividades do grupo Agir para a escola ${ }^{27}$ ), o artigo $8^{\circ}$ contém uma formulação que pode abrir caminho para o cancelamento dos serviços, que até então fora rejeitada pela maioria dos professores dos $1^{\mathrm{o}}$ e $2^{\mathrm{o}}$ graus $^{28}$, mas há muito tempo desejada por alguns reformadores para flexibilizar e libertar a organização escolar. Ao findar as atividades do $\mathrm{CNESCO}^{29}$, um Conselho de Avaliação da Escola é criado (art. 9) sob a dependência direta do ministro, encarregado, agora, de avaliar os estabelecimentos de ensino e não mais as próprias políticas escolares. Por meio dos artigos $10^{\circ}$ até o $12^{\circ}$, todas as recentes ESPE $(2013)^{30}$ são substituídas pelo INSPE, Institutos Nacionais Superiores do Professorado e da Educação que, a considerar pela sua organização e, em especial, o processo de nomeação dos seus diretores e a composição dos seus conselhos, traduzem a vontade de ver o Estado central retomar as ações na formação dos professores.

Por fim, sem poder fazer um panorama completo do projeto, há que consagrar um lugar àquilo que não estava no seu conteúdo inicial, mas que se deve a uma alteração parlamentar proveniente de um membro da maioria, alteração tanto mais oportuna para o ministro quanto vai ao sentido de uma preconização da L'École de demain: "a questão do estatuto das escolas pode ser abordada como desafio central para as missões do diretor da escola, que poderia, assim, tornar-se [...] o responsável hierárquico dos professores da sua escola” (p. 46). A alteração, inicialmente aprovada pela Assembleia com o apoio do Ministro, prevê a experimentação, com base no voluntariado, dos EPSF (Estabelecimentos públicos de saberes fundamentais), reunindo colégios ${ }^{31}$ e escolas primárias sob a direção do diretor do colégio, fazendo dos diretores de escolas adjuntos deste, dotados de um poder hierárquico e com perda de sua autonomia. Isto coloca um desafio para estes funcionários, hostis a

${ }^{26}$ Cf. Céline Alvarez, Les lois naturelles de l'enfant, Paris, Les Arènes, 2016.

27 Plataforma experimental, hospedada pelo Instituto Montaigne, promovendo novos (sic) métodos de aprendizagem da leitura "fundamentadas em uma rigorosa investigação científica" (sic), autorizada à experimentação em 500 salas de aula.

28 Os seus serviços são fixados semanalmente (número de horas de aulas/semana). A carga horária anual é considerada um meio de flexibilizar e, finalmente, de prolongar os tempos de serviço.

${ }^{29}$ Conselho independente criado pela lei de refundação de 2013, Conselho Nacional de Avaliação do Sistema Escolar.

30 Escolas Superiores do Professorado e da Educação, criadas pela Lei de Refundação de 2013.

${ }^{31}$ Primeiro nível do ensino secundário (de 11 a 15 anos). Em comparação à organização do ensino brasileiro, o colégio equivale aos anos finais do ensino fundamental $\left(6^{\circ}\right.$ ao $9^{\circ}$ ano). 
qualquer ideia de perda de autonomia do primário em relação ao secundário (e de instauração de uma hierarquia entre eles e os seus colegas nas escolas) e em relação aos prefeitos, recusando formalmente a separação assim induzida das escolas e dos municípios.

\section{Conclusão ainda que provisória}

Do mesmo modo que o projeto de lei foi alterado em sua análise pelas duas assembleias (nítida supressão do projeto de EPSF, já mencionado anteriormente), uma política está igualmente sujeita a inflexões nem sempre previsíveis, dependentes das reações de apoio, de indiferença ou da oposição que ela suscita. Neste caso, no momento em que as greves anteriores se mantiveram bastante tímidas, é necessário esperar pelas consequências sociais, particularmente a partir do início do ano letivo de 2019. Aliás, os sindicatos dos professores se organizam para fazer valer as suas reivindicações, e - no contexto da crise conhecida como "coletes amarelos", ocorrida no final de 2018 e no início de 2019 - o ministro parece mais disposto ao diálogo.

Na tentativa de decodificação desta lei, é quase impossível resumir a política de J.-M. Blanquer por meio de um único qualificador, uma vez que liberal ou neo-liberal revelar-se-ia bastante impreciso, levando em conta a habilidade do ministro para nos despistar - correndo o risco de confusão - em um movimento coordenado por suas afinidades eletivas. Em contrapartida, se por um atalho pouco acadêmico se diz: política "Neuro-TecnoAutoritária”" com desejos de mudança social praticar-se-ia, ao mesmo tempo, uma escolha que não diz o seu nome; não estamos longe da realidade dos fatos observados.

\section{Referências}

ALVAREZ, Céline. Les lois naturelles de l'enfant, Paris, Les Arènes, 2016.

BLAY, Michel et LAVAL, Christian. Neuropédagogie. Le cerveau au centre de l'école, Paris, Tschann, 2019.

GURGAND, Marc. Un des chercheurs impliqués, in Le Monde.fr, 23.01.2019.

OCDE. PISA: Program for International Student Assessment; PIRLS : Progress in International Reading Literacy.

ROBERT, André D. L'école en France de 1945 à nos jours, Grenoble, PUG, $2^{\mathrm{e}}$ édition augmentée.

\footnotetext{
${ }^{32}$ Cf. também Philippe Champy, Vers une nouvelle guerre scolaire, Paris, La Découverte, 2019.
} 
ROBERT, André D. Le 'projet de modernisation du système éducatif' : prémices proches et lointaines, contexte, processus d'élaboration (été 1974- février 1975) in Gutierrez L. et Legris P., Le collège unique, PUR, 2016. https://doi.org/10.4000/books.pur.45213

ROBERT, André D. Alain Peyrefitte, la rénovation de la pédagogie et le colloque d'Amiens', à paraître. Ouvrage collectif, PUR. 